\title{
Eficiência informacional do mercado de capitais brasileiro em anúncios de fusões e aquisições
}

\author{
Marcos Antônio de Camargos ${ }^{\text {a* }}$, Francisco Vidal Barbosa ${ }^{\mathrm{b}}$ \\ a*Instituto Brasileiro de Mercado de Capitais, Belo Horizonte, MG, Brasil, marcosac@ibmecmg.br \\ bUniversidade Federal de Minas Gerais, Belo Horizonte, MG, Brasil.
}

\begin{abstract}
Resumo
0 objetivo deste artigo é analisar o comportamento dos preços de ações de companhias abertas brasileiras listadas na BM\&FBovespa, nos dias próximos aos anúncios de fusões ou aquisições ( $F \& A s$ ), visando aferir a eficiência informacional semiforte do mercado de capitais brasileiro. Em termos metodológicos, trata-se de um estudo de evento no qual os retornos anormais diários foram calculados utilizando-se o Modelo de Retornos Ajustados ao Mercado. A amostra foi composta por 61 ações preferenciais e 27 ordinárias de companhias brasileiras que empreenderam processos de F\&As entre janeiro de 1996 e dezembro de 2004. Conclui-se que: 1.0 anúncio de uma F\&A contém informação relevante para a precificação das ações no mercado; 2. Possivelmente ocorreu uso de informações privilegiadas (indícios); 3. 0 mercado comportou-se de maneira eficiente informacionalmente, tanto para as ações preferenciais quanto para as ordinárias, no que se refere à velocidade do ajuste ao anúncio; 4.0 mercado reagiu de maneira diferenciada para ações preferenciais e ordinárias, com queda para as primeiras e elevação para essas últimas.
\end{abstract}

Palavras-chave

Eficiência de mercado. Fusões e aquisições. Estudo de evento. Insider trading.

\section{Introdução}

A Hipótese da Eficiência de Mercado (HEM) vem sendo um dos paradigmas da teoria de Finanças, desde que o interesse por ela foi revivido no final dos anos 50 e início dos anos 60, sob o nome de random walk theory, na literatura de Finanças e teoria das expectativas racionais no mainstream da literatura Econômica (Jensen, 1978). A partir de então, passou-se a conferir maior atenção aos estudos do comportamento dos preços no mercado de capitais, ocorrendo uma convergência de estudos para a verificação da velocidade e precisão do ajustamento dos preços dos títulos a novas informações.

A partir dos estudos de Roberts (1967) e Fama (1970), a HEM ganhou espaço no meio acadêmico, passando a ser um dos pilares da Moderna Teoria de Finanças, ganhando, desde então, robustez teórica e um conjunto de evidências empíricas. Ela tem como pressuposto básico que as informações relevantes sobre determinada empresa são incorporadas de forma rápida e precisa aos preços das ações no mercado. Dessa maneira, um mercado eficiente refletiria o conjunto de informações existentes, reduzindo, portanto, assimetria de informações e impossibilitando oportunidades de arbitragem por parte dos participantes desse mercado.

Em um mercado com essas características, as informações são amplamente acessíveis a todos os agentes e disponibilizadas sem custos significativos. Assim, nenhum participante conseguiria se utilizar de padrões de comportamento do mercado para obter retornos extraordinários de forma sistemática. Do ponto de vista da transparência e da igualdade de condições e competição (fair game), essa característica é desejável e pode contribuir sobremaneira para alavancar o desenvolvimento econômico de um país, com base em um modelo de economia de mercado.

0 tema abordado neste artigo se insere dentro dos estudos do comportamento dos preços das ações de companhias abertas no mercado de capitais, quando da divulgação de alguma informação relevante. 
Trata-se da análise de como o mercado se comporta no que se refere à antecipação, absorção, avaliação e ajuste dos preços quando da divulgação desse tipo de informação. Por informações relevantes, entendem-se aquelas capazes de afetar (positiva ou negativamente) o fluxo de caixa ou o desempenho futuro de uma determinada empresa e, consequentemente, a expectativa dos investidores em relação aos preços praticados no mercado. Dentro do leque dessas informações, destacam-se o vencimento de opções, bonificações, subscrição de ações, pagamento de dividendos, anúncios trimestrais, semestrais ou anuais de lucros, desdobramento de ações, fusões e aquisições, entre outros. No contexto desta pesquisa, a eficiência do mercado foi analisada quando da divulgação de processos de fusões e aquisições (F\&As) de empresas brasileiras.

Os processos de F\&As constituem um dos eventos corporativos mais controversos e difíceis, pois, além dessas características, são inúmeras as variáveis que devem ser consideradas e controladas, antes, durante e após sua divulgação, fazendo com que o mercado de capitais avalie com cautela o desdobramento de uma união empresarial. Muitas vezes, o mercado não é capaz de interpretar, descontar e incorporar aos preços todas as informações relevantes para avaliar uma $\mathrm{F} \& A$, por não conseguir prever quão ruim será 0 seu resultado, ou mesmo se o valor ou prêmio pago foi elevado ou não.

Em um mercado de capitais eficiente, a divulgação de um processo de F\&A deve ter incorporado aos preços das ações, as expectativas dos investidores quanto aos resultados futuros da combinação empresarial, sejam positivas, negativas ou de indiferença. Quanto mais rápida e precisa for essa incorporação, mais eficiente é tido o mercado.

A eficiência do mercado brasileiro tem sido analisada por meio de vários eventos, dentre os quais os processos de F\&As. Destaca-se que esses estudos apresentam diferentes metodologias de cálculo do retorno anormal e chegaram a conclusões contraditórias. Os resultados encontrados por Bueno et al. (2000) e por Camargos \& Barbosa (2006) vão na direção de que o mercado de capitais brasileiro não foi eficiente ao precificar anúncios de F\&As; enquanto que, em estudo posterior, Camargos \& Barbosa (2007) concluíram que o mercado se comportou de maneira eficiente. Dessa maneira, esta pesquisa vem acrescentar novas evidências às pesquisas sobre a HEM na divulgação de F\&As, ao constatar que o mercado brasileiro se comportou de maneira eficiente informacionalmente, tanto para as ações preferenciais quanto para as ordinárias, no que se refere à velocidade do ajuste ao anúncio, no período analisado, destacando-se que, além da separação entre ações ordinárias e preferenciais, a amostra utilizada é maior do que esses três estudos.

Um dos fatores que justificam o estudo é o quadro de mudanças ocorridas na economia brasileira a partir da metade da década passada (estabilização econômica), cujas consequências atingiram os arranjos produtivos, as forças de mercado e os padrões concorrenciais, fruto direto do aumento dos Investimentos Diretos Estrangeiros - IDE - e da atividade de fusões, aquisições e outras alianças estratégicas. Isso sem mencionar os avanços legais (Brasil, 1976, 2001) e as inovações implantadas pela então Bovespa em 2001, com a criação dos segmentos diferenciados de governança corporativa. Parte-se do pressuposto de que essas mudanças tenham reflexos diretos no comportamento do mercado de capitais brasileiro.

São três as motivações desta pesquisa. A primeira seria a importância do tema dentro da teoria financeira; a segunda, a escassez de pesquisas empíricas sobre ele, no contexto das F\&As no mercado brasileiro; e a terceira seria a possível contribuição empírica que poderia trazer, tendo em vista a amostra utilizada ser maior do que todas as pesquisas da literatura nacional consultada. Além da contribuição para um melhor entendimento dos processos de F\&As no contexto da economia brasileira.

Nesse contexto, o objetivo deste artigo é analisar o comportamento dos preços de ações de companhias abertas listadas na BM\&FBovespa, nos dias próximos aos anúncios de fusões ou aquisições, ocorridos no período compreendido entre janeiro de 1996 e dezembro de 2004, visando aferir a eficiência informacional semiforte do mercado de capitais brasileiro. Na sequência, é apresentado o quadro teórico de referência, seguido dos procedimentos metodológicos e análise e discussão dos resultados nas seções 2 , 3 e 4, respectivamente. Encerra-se com as conclusões e considerações finais na seção 5, seguidas das referências consultadas.

\section{Referencial teórico}

\subsection{Fusões e aquisições e a eficiência de mercado}

Fusão ou consolidação é um dos métodos pelo qual uma firma pode adquirir outra. Além da fusão, a aquisição pode ser feita por meio da compra de ações ou ativos. 0 pagamento pode ser feito em dinheiro, ações ou outros títulos. Já o processo de negociação pode ser iniciado de duas maneiras: 
1. Oferta privada de aquisição da administração da empresa adquirente à administração ou ao conselho de administração da empresa-alvo, denominada pela literatura financeira de tomada amigável do controle corporativo; 2. Oferta pública de aquisição (tender offer), feita pela firma adquirente diretamente aos acionistas da empresa-alvo, na tentativa de comprar um determinado número de ações a um preço específico em uma data estipulada, que lhe garanta o controle daquela empresa. Situação chamada de tomada hostil de controle corporativo (takeover) pela literatura financeira (Brealey \& Myers, 1995).

Ross et al. (2002) destacam as distinções básicas entre fusão ou consolidação e aquisição: 1. Em uma fusão, pode haver a criação de uma nova firma (consolidação), enquanto, na aquisição, uma das empresas envolvidas geralmente mantém sua identidade jurídica; 2 . Na fusão, geralmente a forma de pagamento utilizada é uma permuta de ações, enquanto, na aquisição, a forma de pagamento pode ser dinheiro, ações ou outros títulos; 3 . Na fusão, as firmas geralmente são do mesmo setor, têm a mesma atividade-fim, enquanto, nas aquisições, é comum as firmas serem de setores diferentes.

Segundo a teoria econômica neoclássica, as F\&As podem ser vistas como uma tentativa das empresas em melhorar a eficiência, diante das frequentes alterações no ambiente de negócios, dentre as quais se destacam: legislação antitruste, desregulação ou abertura de mercado, internacionalização, aumento da competição, maior integração dos mercados financeiros e de capitais em nível mundial, entre outros fatores (Jovanovic \& Rousseau, 2002).

Tal atividade guarda relação estreita tanto com o surgimento, crescimento e "humor" do mercado de capitais quanto com o surgimento das grandes corporações, denominadas por Berle Junior \& Means (1932) como "corporação moderna". Assim, sua origem teórica se fundamenta nas diversas teorias que explicam a origem e o crescimento da firma. Sobre isso, Waack (2000) assinala que os maiores declínios na atividade de F\&A coincidem com os períodos de menor desempenho dos mercados de capitais, sinalizando que as F\&As estão diretamente relacionadas ao aumento da competição, típica de períodos economicamente menos favoráveis ou, em contraposição, correspondem a períodos em que o vendedor tem maior chance de fazer uma boa venda (maior valor do negócio).

A literatura Econômico-Financeira internacional, baseada principalmente no mercado norte-americano, assinala quatro ondas de fusões e aquisições (F\&As), que desempenharam um papel relevante em âmbito mundial na concentração de capitais e consolidação de setores econômicos. Foram elas: The Great
Merger Wave (1887-1904); The Merger Movement (1916-1929); The 1960s Conglomerate Merger Wave e The Wave of the 1980s (Scherer \& Ross, 1990). Mais recentemente, autores como Jovanovic \& Rousseau (2002) desdobram essa última onda em uma quinta, denominada de onda dos anos 90, que tem apresentado uma nova dinâmica na condução desses processos, muito mais focada na obtenção de sinergias e ganhos (retorno da busca pela função objetiva da firma, de maximização da riqueza), frente à tentativa de se corrigir os erros cometidos na onda dos anos 60, na qual a diversificação em conglomerado criou empresas fortes, de atuação mundial, mas ineficientes, de baixa mobilidade e lucratividade.

Na perspectiva econômica, Pinto Junior \& lootty (2005) salientam que os estudos sobre F\&As se dividem em duas vertentes principais: 1. Economia Industrial: avalia o desempenho das F\&As por meio da análise dos dados contábeis das empresas envolvidas nas operações; 2. Financeira: também denominado genericamente estudo de evento, examina o desempenho das empresas envolvidas nas operações de F\&As a partir do comportamento do preço de suas ações em períodos anteriores e posteriores à transação, comparando com um grupo de controle.

Segundo Firth (1980), no exame da rentabilidade dos processos de F\&As, é comum usar a teoria da eficiência de mercado por ela fornecer uma medida do retorno dos acionistas. Assumindo um mercado eficiente, pode-se medir o movimento dos preços de ações ao redor do tempo de um evento específico, obtendo-se uma medida direta do impacto econômico desse evento e do aumento ou redução na riqueza dos acionistas.

No que diz respeito ao conteúdo informacional do anúncio de uma F\&A, Halpern (1983) assinala que uma fusão ou proposta pública de compra (tender offer) fornece uma boa quantidade de sinais, todos os quais geram informações que estão refletidas nos preços dos títulos. Esses sinais trazem informações sobre o próprio evento, a identidade do adquirente e forma de pagamento, entre outras, sendo muito difícil desvencilharem o impacto nos preços dos títulos de todos esses sinais e, assim, avaliar a motivação subjacente a uma F\&A.

0 mercado de capitais brasileiro apresenta um número reduzido de F\&As quando comparado com outros mais desenvolvidos. Segundo dados da KPMG (2010), entre 1994 e 2006, ocorreram 4.032 processos de $\mathrm{F} \& \mathrm{~A}$, dos quais, 1.682 foram domésticos e 2.350 foram do tipo cross-border ou transfronteiriços. Alguns dos fatores que explicam esse reduzido número de operações de F\&As seriam 
a legislação que inibe, por exemplo, as tomadas de controles hostis, mas, principalmente, por ainda apresentar uma carência de recursos financeiros de longo prazo, ter elevadas taxas de juros, baixa liquidez acionária e maior free float das ações preferenciais entre outros.

\subsection{A Hipótese da Eficiência de Mercado e os anúncios de $F \& A s$}

A Hipótese da Eficiência de Mercado (HEM) pressupõe a análise da velocidade e qualidade, direção e magnitude do ajustamento dos preços às novas informações. Vários eventos ou informações podem influenciar os preços, e as magnitudes das alterações dependem de fatores como: contexto do mercado, relevância da informação, tempo para interpretação e absorção pelo mercado. Destacando-se que a ocorrência de um evento envolvendo as ações de uma empresa terá conteúdo informacional ou valor como informação somente se acrescentar algo que ainda não é conhecido (Copeland \& Weston, 1988).

Para Brealey \& Myers (1995), um mercado eficiente é aquele em que os participantes formam expectativas com relação aos preços com base em toda informação disponível sobre eventos relevantes que possam influenciar de alguma forma o valor dos ativos no mercado. $\mathrm{Ou}$, em outras palavras, um mercado eficiente de capitais é aquele no qual os preços dos títulos refletem completamente as informações disponíveis.

Segundo Haugen (1995), um mercado é eficiente quando as informações relevantes em um período de tempo $t\left(l_{t}\right)$ sobre as empresas participantes desse mercado não alterar o retorno esperado de investimentos nele. Isso significa dizer que os preços sempre refletem de maneira completa e instantânea o fluxo de informações disponíveis. Dessa forma, os preços das ações nesse mercado se ajustam no momento em que as informações relevantes são disponibilizadas publicamente. Além disso, em um mercado eficiente não há a possibilidade de ocorrer estratégias de negociação baseadas no fluxo de informações passadas, que proporcionem ganhos anormais.

$$
E\left(R_{j(t+1)} / I_{t}\right)=E\left(R_{j(t+1)}\right)
$$

em que $E\left(R_{j(t+1)} / I_{t}\right)$ e $E\left(R_{j(t+1)}\right)$ são, respectivamente, esperança de retorno do ativo $j$ no período $t+1$, dado o conjunto de informações disponíveis em $\mathrm{t}$ $\left(I_{t}\right)$ e esperança de retorno do ativo $j$ no período $t+1$.

A Hipótese da Eficiência de Mercado está, assim, baseada na afirmação de que a cotação de uma ação reflete as informações disponíveis a respeito da firma que a emitiu. Dessa forma, novas informações afetarão sua cotação de maneira mais rápida ou mais lenta. Ela requer que os retornos observados no mercado de capitais apresentem ausência de quaisquer regularidades ou padrões de comportamento no mercado (anomalias). A existência de alguma sazonalidade nos retornos resultaria em ineficiência informacional, pois um investidor poderia se utilizar desse comportamento regular para implantar estratégias de negociação que lhe garantisse ganhos anormais.

Na operacionalização do conceito da eficiência do mercado Fama (1970), definiram-se três formas de eficiência, considerando o subconjunto de informações disponíveis, diferenciando-as quanto à relevância no processo de precificação de ativos. São elas: fraca (preços refletem completamente as informações sobre o histórico do comportamento dos preços dos títulos); semiforte (preços refletem além do histórico do comportamento dos preços, todas as informações publicamente disponíveis); e forte (preços refletem todas as informações disponíveis: históricas, públicas e privadas). Os três tipos de eficiência de mercado e o cunjunto de informações que refletem são apresentados na Figura 1.

De maneira geral, os testes para se aferir a eficiência na forma semiforte são chamados de estudos de eventos, os quais consistem em verificar o comportamento dos preços de títulos nos dias próximos à divulgação de informações relevantes. Isso é feito por meio da análise do retorno anormal (RA) dos títulos no mercado que foram afetados por um mesmo evento em determinado período. 0 RA é a diferença entre o retorno do título e o retorno de mercado (retorno normal ou esperado em condições normais, sem a ocorrência do evento).

$R A_{i t}=R_{i t}-E\left(R_{i t}\right)$

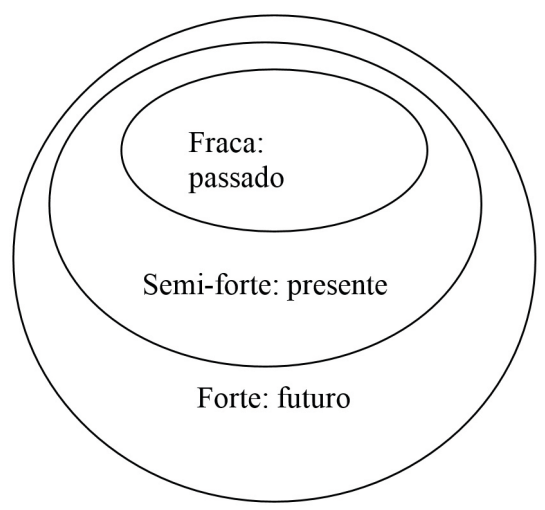

Figura 1. Tipos de eficiência. Fonte: Elaborada pelos autores. 
em que $R A_{i t}, R_{i t}$ e $E\left(R_{i t}\right)$ são respectivamente o retorno anormal, retorno observado e retorno normal do ativo i para o período t, afetado pelo evento em estudo. Como a eficiência é aferida para o mercado e não para uma empresa em específico, torna-se necessária a acumulação dos retornos anormais de todas as empresas analisadas, conforme apresentado na metodologia, chegando-se ao retorno anormal acumulado $\left(R A A_{i t}\right)$.

A literatura de Finanças apresenta vários modelos de cálculo do retorno normal, que vão desde modelos ajustados ao mercado, até modelos mais sofisticados, ajustados ao risco e ao mercado, no qual se utiliza o $C A P M$. A escolha de um em detrimento dos outros é subjetiva e se baseia no critério da parcimônia, uma vez que não há melhorias significativas na utilização de metodologias mais sofisticadas, tanto com dados de mercados desenvolvidos (Brown \& Warner, 1980, 1985) quanto dados do mercado brasileiro (Kloeckner, 1995).

Fundamentado no que foi discutido acima, para se aferir da eficiência do mercado de capitais brasileiro na sua forma semiforte foram testadas as seguintes hipóteses:

$\mathrm{H}_{0}$ - o retorno anormal acumulado $\left(R A A_{i t}\right)$ das empresas brasileiras que passaram por processos de fusão ou aquisição na data zero e no dia seguinte não é estatisticamente igual a zero $\left(R A_{i_{t_{01}}} \neq 0\right)$, sinalizando que o mercado comportou-se de maneira ineficiente;

$\mathrm{H}_{1}$ - o retorno anormal acumulado $\left(R A A_{i t}\right)$ das empresas brasileiras que passaram por processos de fusão ou aquisição na data zero e no dia seguinte é estatisticamente igual a zero $\left(R A_{i t_{1}}=0\right)$, sinalizando que o mercado comportou-se de maneira eficiente.

No que se refere à forma semiforte, aferida quando da divulgação de informações relevantes no mercado brasileiro, Novis Neto \& Saito (2002), Procianoy \& Antunes (2001), Leite \& Sanvicente (1990) e Perobelli e Ness Junior (2000) encontraram evidências contrárias, enquanto Cordeiro et al. (1999) e Schiehll (1996) concluíram em seus estudos que o mercado de capitais brasileiro comportou-se de maneira eficiente na forma semiforte.

Em relação à HEM, quando da divulgação de F\&As, Bueno et al. (2000), investigando o uso de informações privilegiadas (insider trading) antes do anúncio de F\&As, identificaram uma ineficiência do mercado em precificar as ações. De maneira similar, as evidências encontradas por Camargos \& Barbosa (2006) mostraram que o mercado não se comportou de maneira eficiente no período analisado. Enquanto que, em estudo posterior, utilizando outro modelo de cálculo do retorno anormal, Camargos \& Barbosa
(2007) encontrou evidências favoráveis à HEM na forma semiforte.

\subsection{Insider Trading e a Hipótese da Eficiência de Mercado}

Para Ross et al. (2002), a HEM apresenta implicações tanto para investidores quanto empresas. Os primeiros devem obter somente uma taxa normal de retorno, uma vez que a informação é refletida imediatamente nos preços. A tomada de conhecimento da informação apenas no momento em que é divulgada não traz vantagem alguma para o investidor. 0 preço se ajusta antes que ele tenha tido tempo de comprar ou vender a ação com ganhos anormais. Enquanto que as empresas devem esperar receber o valor justo pelos títulos vendidos.

$\mathrm{Na}$ perspectiva da antecipação e uso de informações por parte de alguns agentes do mercado, essas implicações ficam comprometidas, pois poderia proporcionar, por um lado, ganhos anormais e, por outro, dificultar a precificação dos títulos no mercado. 0 comportamento anormal dos preços dos títulos nos dias próximos a um evento ou divulgação importante - no caso, o anúncio de uma fusão ou aquisição - pode ser explicado pelo uso de informações privadas (insider information), visando obter retornos anormais (acima da média de mercado). Quando a avaliação e ajuste ocorrem de forma imprecisa e gradual, investidores conseguem arbitrar até que os preços cheguem a um novo patamar de equilíbrio. Nesse ajuste, o comportamento dos preços dos títulos deixa de ser um fair game, pois aqueles que detêm e se utilizam de informações privilegiadas para negociações no mercado ganham, enquanto que aqueles que não as detêm deixam de ganhar.

Segundo Eizirik (1983), insider trading é a utilização de informações relevantes sobre uma firma por parte das pessoas que, por força do exercício profissional, estão por dentro de seus negócios, para transacionar com suas ações antes que tais informações sejam de conhecimento do público. $\mathrm{Na}$ perspectiva de um mercado eficiente, o insider compra ou vende no mercado a preços que ainda não estão refletindo o impacto de determinadas informações sobre a companhia, que são de seu conhecimento exclusivo.

Se, por um lado, a possibilidade de operações dessa natureza implica que o mercado de capitais é ineficiente no tocante à velocidade de ajuste dos preços a um novo conteúdo informacional, por outro, significa que algum agente de mercado está se utilizando do seu poder, posição hierárquica ou 
do seu acesso direto a informações importantes para auferir ganhos anormais, caracterizando uma situação de uso de informações privadas e assimetria de informação entre os participantes do mercado. Assimetria essa que, quando ocorre entre o agente (administrador, gerente) e o principal (acionistas), resulta em custos significativos de agência oriundos de interesses conflitantes.

Decorre daí que a presença de ineficiências no mercado, assimetrias de informação entre os diferentes investidores e conflitos de agência, podem causar interferências na relação entre o anúncio e a reação do mercado a uma nova informação que é tornada pública. É a análise do comportamento dos preços das ações ao redor dos anúncios de F\&As e a suposição da inexistência dessas interferências que norteiam esta pesquisa.

Fundamentado nessa discussão, para se identificar a prática do insider trading nos processos de F\&As estudados, foram testadas as seguintes hipóteses:

$\mathrm{H}_{3}$ - o retorno anormal acumulado $\left(R A A_{i t}\right)$ das empresas que passaram por processos de fusão ou aquisição entre os dias -5 e - 1 não é estatisticamente igual a zero $\left(R A_{i t_{s,-1}} \neq 0\right)$, sinalizando que ocorreu insider trading;

$\mathrm{H}_{4}$ - o retorno anormal acumulado $\left(R A A_{i t}\right)$ das empresas que passaram por processos de fusão ou aquisição entre os dias -5 e -1 é estatisticamente igual a zero $\left(R A_{i t_{-5,-1}} \neq 0\right)$, sinalizando que não ocorreu insider trading.

\section{Metodologia}

Esta pesquisa é do tipo descritiva ao ter como objetivo principal a descrição das características de determinado fenômeno ( $F \& A$ ) e o estabelecimento de relações entre variáveis. Trata-se também, de uma pesquisa quantitativa, baseada em dados secundários, cujo objetivo foi identificar o comportamento do mercado de capitais quando do anúncio de F\&As no intuito de aferir a sua eficiência na forma semiforte. Foi utilizada a técnica de pesquisa ex-post-facto, pois foram analisados fatos ocorridos no passado, após as variáveis terem interferido sobre o objeto de pesquisa, não sendo possível a interferência do pesquisador sobre as variáveis analisadas (Cooper \& Schindler, 2003).

A pesquisa é também do tipo cross-section, por ter um mesmo conjunto de empresas brasileiras de capital aberto analisadas em um período específico de tempo de nove anos. Foram analisados processos de F\&As ocorridos após a implantação do Plano Real, por se tratar de um período de relativa estabilidade monetária da economia brasileira, evitando assim possíveis vieses da análise de um período anterior.
Conforme Martins (2002), os métodos de amostragem se dividem em: 1. probabilístico: no qual a coleta dos dados se dá de maneira aleatória, sem nenhuma interferência do pesquisador; e 2. não probabilístico: no qual não existe aleatoriedade na coleta dos dados. Sobre esse segundo método, acrescenta que a amostragem pode ser por conveniência (baseada na disponibilidade de dados) ou por julgamento (do pesquisador). Na definição da amostra desta pesquisa, foi utilizado método não probabilístico com amostragem por conveniência e por julgamento, no intuito de obter o máximo de dados e informações (empresas) para serem analisadas.

As unidades de análise foram companhias de capital aberto listadas na BM\&FBovespa, que passaram por processos de F\&As após janeiro de 1996 e as unidades de observação foram cotações das ações dessas companhias no mercado. Optou-se por utilizar o lbovespa como proxy do mercado, tendo em vista que ele é o mais importante indicador do comportamento / desempenho do mercado de capitais brasileiro, além de ser o mais utilizado em pesquisas no país.

\subsection{O método}

Campbell et al. (1997) descrevem as etapas de um estudo de evento como sendo: definição do evento, critérios de seleção, cálculo do retorno anormal, procedimentos de estimação, procedimentos de teste, análise dos resultados e conclusão, descritos a seguir.

Evento: conforme já mencionado, foram os processos de F\&As, tendo em vista o impacto imediato que causam nos preços das ações das empresas envolvidas quando do seu anúncio. Foram objetos deste estudo somente as companhias de capital aberto não financeiras que passaram por processos de fusões e aquisições entre janeiro/1996 e dezembro/2004, cujas ações estavam listadas na BM\&FBovespa. A cotação das ações e a [cotação] do lbovespa (proxy do retorno de mercado) foram obtidas do banco de dados Economática. No cálculo do retorno anormal (RA), foi utilizado o valor de fechamento diário de ações preferenciais (PN) e ordinárias (ON) em Real, ajustado por proventos, inclusive dividendos.

Critérios de seleção da amostra: 1. Identificação do dia da divulgação da F\&A ao mercado na base de dados economática. Nesta pesquisa, foi considerada como "data do evento" a aprovação nas assembleias de acionistas, por ser esse o momento do comunicado oficial e apresentação aos acionistas da negociação e do processo da F\&A; 2. Valores acima de R\$5.000.000; 3. Liquidez 
acionária. As empresas que apresentaram períodos longos sem negociação/cotação (quinze dias úteis ou mais) foram excluídas da amostra, uma vez que a baixa liquidez poderia influenciar os resultados; 4. Companhias não financeiras. Este último critério se deve ao fato de que esta pesquisa faz parte de outra mais abrangente, que utilizou demonstrativos contábeis. Dessa forma, os autores estão cientes de que ele não seria necessário, em se tratando do uso de retorno acionário como unidade de análise. Foram selecionados intencionalmente setenta e dois (72) processos de F\&As, e, com base nos critérios acima, chegou-se à amostra final, apresentada na Tabela 1. Salienta-se que algumas ações ordinárias das empresas aí descritas não constaram da amostra de ações preferenciais por estar a companhia emissora listada no Novo Mercado, tendo ela, portanto, somente esse tipo de ação.

Devido à maior liquidez, as ações preferenciais tiveram um número bem superior ao das ordinárias, 61 ações das primeiras (PN), contra 27 ações dessas últimas (ON), conforme se vê nas Tabelas 2 e 3 .

Cálculo do retorno anormal (RA): foram utilizados retornos diários, os quais, segundo Brown \& Warner (1980, 1985), permitem ao pesquisador isolar mais efetivamente a reação do mercado a um evento particular que tenha sua data de divulgação conhecida. 0 RA é obtido do retorno da ação antes de um evento, subtraído do retorno esperado sem que ocorra o evento, do qual se pode subentender que ao utilizar o retorno de mercado com o lbovespa como proxy do retorno esperado, espera-se que as empresas, para terem retornos anormais, deveriam superar o retorno de mercado. 0 RA foi calculado utilizando o Modelo de Retornos Ajustados ao Mercado, que consiste em se encontrar a diferença do retorno da ação em relação ao retorno do índice de mercado (lbovespa) numa mesma data, utilizando-se a forma logarítmica expressa por,

$$
R A_{i t}=L N\left(\frac{\frac{P_{t+1}}{P_{t_{0}}}}{\frac{I b o v_{t+1}}{I b o v_{t_{0}}}}\right)
$$

que pode ser reescrita como:

$$
R A_{i t}=L N\left(\frac{P_{t+1}}{P_{t_{0}}}\right)-L N\left(\frac{I b o v_{t+1}}{I b o v_{t_{0}}}\right)
$$

sendo: $P_{t_{0}}=$ cotação da ação em uma data base; $P_{t+1}=$ cotação da ação no mercado em um dia $\mathrm{t}$ posterior; Ibov $_{t_{0}}=$ cotação do lbovespa em uma data base; $I b o v_{t+1}=$ cotação do lbovespa em um dia t posterior.
Procedimento de estimação: a janela de análise compreendeu cinco dias entorno do anúncio da F\&A (dia da divulgação). Ou seja, cinco anteriores e posteriores. Uma vez calculados os retornos anormais, estes foram acumulados (somados) em cada um dos dias relativos para todas as empresas. A agregação dos retornos anormais foi feita pela técnica do Retorno Anormal Acumulado - RAA -, conforme assinalado por Campbell et al. (1997), com os retornos sendo acumulados pelos títulos [equação 5] e no tempo [equação 6]:

$$
\begin{aligned}
& R A A_{i t}=\sum_{t=1}^{n} R A_{i t} \\
& \overline{R A A}_{t\left(t_{1}, t_{2}\right)}=\frac{1}{N} \sum_{i=1}^{n} R A A_{i}\left(t_{1}, t_{2}\right)
\end{aligned}
$$

sendo: $\overline{R A A}_{t\left(t_{1}, t_{2}\right)}=$ média do RAA para todas as empresas no período t entre os dias $t_{1}$ e $t_{2}$ (janelas); $\mathrm{n}=$ número de empresas; $R A A_{t\left(t_{1}, t_{2}\right)}=$ retorno acionário anormal da empresa i no dia t.

No que se refere ao procedimento de teste, foi analisada a significância estatística do RAA em cada um dos dias dentro da janela de dez dias, visando identificar se são diferentes de zero. Foi utilizado o teste t (t de Student). Caso fossem constatados retornos anormais significantes e diferentes de zero, nos dias $t_{0}$ e $t_{+1}$, poder-se-ia concluir que o mercado comportou-se de maneira ineficiente, no que se refere à rapidez e à precisão da incorporação do anúncio de uma $\mathrm{F} \& \mathrm{~A}$ nos preços das ações das empresas analisadas. Caso isso ocorresse nos dias anteriores $(-5$ a -1$)$ seria um sinal de uso de informação privilegiada. Cabe salientar que a definição da janela a ser analisada no entorno da divulgação de uma informação relevante em um estudo de evento é subjetiva e arbitrária, dependendo do evento estudado e dos objetivos que se almejam com essa metodologia (Camargos \& Barbosa, 2003). Como nesta pesquisa o objetivo era identificar o comportamento da cotação acionária quando da divulgação de uma $F \& A$, optou-se por restringir a janela de observação a cinco dias depois do anúncio, pois um período maior poderia englobar outros eventos corporativos relevantes, além do fato de que o ajuste dos preços para se aferir a eficiência do mercado deve ser rápido, restringindo assim, a possibilidade de arbitragem.

Análise dos resultados e conclusão: são apresentados nas seções seguintes.

Os cálculos e a acumulação do retorno anormal foram feitos utilizando o Microsoft Excel versão Office-2003, enquanto o teste $t$ foi efetuado utilizando o Statistical Package for the Social Sciences - SPSS, versão 13.0. 
Tabela 1. Amostra de processos de F\&As analisados (continua).

\begin{tabular}{|c|c|c|c|}
\hline $\mathrm{N}^{\circ}$ & Adquirente & Adquirida & Data \\
\hline 1 & Sadia S/A & Só Frango Produtos Alimentícios & $23 / 12 / 04$ \\
\hline 2 & Aços Villares S/A & Tecno-Logos S/A & $26 / 11 / 04$ \\
\hline 3 & Cemig S/A & Rosal Energia S/A & $25 / 11 / 04$ \\
\hline 4 & WEG S/A & Nantong Electric Motor Fact. & $08 / 11 / 04$ \\
\hline 5 & Suzano Papel e Celulose S/A & & \\
\hline 6 & VCP S/A & Ripasa S/A & $11 / 10 / 04$ \\
\hline 7 & Gerdau S/A & North Star & 09/09/04 \\
\hline 8 & CVRD S/A & Noranda lnc. & $16 / 06 / 04$ \\
\hline 9 & Brasil Telecom S/A & Internet Group (1G) & $18 / 05 / 04$ \\
\hline 10 & Belgo-Mineira S/A & Acindar (Arg) & $10 / 05 / 04$ \\
\hline 11 & Petrobras Química S/A & Petroquímica Triunfo & $03 / 05 / 04$ \\
\hline 12 & CVRD S/A & Caemi S/A & $31 / 03 / 04$ \\
\hline 13 & Coteminas S/A & Tecidos Santanense S/A & $11 / 03 / 04$ \\
\hline 14 & Lojas Americanas S/A & Site Shoptime & 04/03/04 \\
\hline 15 & Interbrew & Ambev S/A & $03 / 03 / 04$ \\
\hline 16 & Copel Participações S/A & Centrais Elétricas R. Jordão S/A & 18/12/03 \\
\hline 17 & Ultrapar Participações S/A & Shell Gás & $08 / 08 / 03$ \\
\hline 18 & CSN S/A & Tangua Incorporated (Panamá) & $17 / 07 / 03$ \\
\hline 19 & Aracruz Celulose S/A & Riocell S/A & $30 / 05 / 03$ \\
\hline 20 & Saraiva S/A & Formato Editorial & 08/05/03 \\
\hline 21 & Petrobras S/A & Perez Companc S/A (ARG) & $20 / 12 / 02$ \\
\hline 22 & Telemar S/A & Pagasus Telecom & $30 / 10 / 02$ \\
\hline 23 & Gerdau Metalúrgica S/A & Trefilaria Republic (USA) & $18 / 07 / 02$ \\
\hline 24 & Fras-le S/A & Meritor Heavy Vehicle Systems & $18 / 07 / 02$ \\
\hline 25 & Opp. Produtos Petroquímicos, Copeme Petroquímica, 52114 Participações & Braskem S/A & $31 / 05 / 02$ \\
\hline 26 & Metal Leve S/A & Mahle MMG Industria e Comércio Ltda. & $24 / 04 / 02$ \\
\hline 27 & Embraer S/A & Celsius Aerotech & 04/01/02 \\
\hline 28 & Suzano Papel e Celulose S/A & Bahia Sul S/A & $22 / 01 / 01$ \\
\hline 29 & Embratel Part. S/A & Acessonet Ltda. (UOL) & $10 / 11 / 00$ \\
\hline 30 & WEG S/A & Fáb. Motores Argentina (Intermatic) e México (da ABB) & $25 / 07 / 00$ \\
\hline 31 & Klabin S/A & lgaras $S / A$ & $24 / 07 / 00$ \\
\hline 32 & Brasil Telecom S/A & TBS Participações S/A & $17 / 07 / 00$ \\
\hline 33 & CVRD S/A & Samitri S/A & $30 / 05 / 00$ \\
\hline 34 & Acesita S/A & Amorim Distribuidora S/A & $12 / 05 / 00$ \\
\hline 35 & Perdigão S/A & Frigoríficos Batávia & $02 / 03 / 00$ \\
\hline 36 & Cemig $\mathrm{S} / \mathrm{A}$ & Hidroelétrica Sá Carvalho (Acesita) & $02 / 03 / 00$ \\
\hline 37 & Sadia S/A & Granja Resende Ltda & $27 / 12 / 99$ \\
\hline 38 & Telesp S/A & СТВС & $30 / 11 / 99$ \\
\hline 39 & Globex Utilidades S/A & Kit Eletro & $09 / 09 / 99$ \\
\hline 40 & Alpargatas/Santista S/A & Machasa S/A (Chilena) & $03 / 08 / 99$ \\
\hline 41 & Brahma S/A & Antártica S/A & $01 / 07 / 99$ \\
\hline 42 & Marcopolo S/A & Ciferal & $26 / 05 / 99$ \\
\hline 43 & Gerdau S/A & FLS Holding / AmeriSteel Corporation & $08 / 04 / 99$ \\
\hline 44 & VCP S/A & Ribeirão Grande S/A & $05 / 02 / 99$ \\
\hline 45 & Usiminas S/A & Cosipa S/A & $27 / 08 / 98$ \\
\hline 46 & Cia. Brasileira Distribuição (CBD) S/A & Rede Barateiro de Supermercados & 20/05/98 \\
\hline 47 & Usinor Sacilor (FRA) & Acesita S/A & $27 / 05 / 98$ \\
\hline 48 & Gerdau Metalúrgica S/A & Puntana Sipsa (Arg.) & $16 / 12 / 97$ \\
\hline 49 & Cataguazes Leopoldina S/A & Energip S/A & $04 / 12 / 97$ \\
\hline 50 & Whirlpool Corporation & Brasmotor S/A & 19/09/97 \\
\hline 51 & Whirlpool Corporation & Multibrás S/A & 19/09/97 \\
\hline 52 & Bombril S/A & Cirio & $24 / 07 / 97$ \\
\hline 53 & Coteminas S/A & Cotenor S/A e Cebratex S/A & 30/06/97 \\
\hline 54 & Eternit $S / A$ & Duralit S/A & $27 / 12 / 96$ \\
\hline 55 & Salgema, Cia Petroquímica de Camaçari, Cia Química do Recôncavo & Trikem S/A & $12 / 12 / 96$ \\
\hline 56 & Paranapanema S/A & Minera Yauliyacu (Peru) & $09 / 12 / 96$ \\
\hline 57 & Inepar Construções S/A & Sade Vigesa Ind. e Serv. S/A & 17/07/96 \\
\hline 58 & Grupo de lnvestidores & Estrela S/A & $25 / 04 / 96$ \\
\hline 59 & Acesita S/A & CST S/A & $24 / 04 / 96$ \\
\hline 60 & Avipal S/A & CCGL Laticínios S/A (ELEGE) & $22 / 04 / 96$ \\
\hline 61 & Belgo-Mineira S/A & Dedini S/A Siderúrgia & $22 / 02 / 96$ \\
\hline 62 & Randon Participações S/A & Fras-le S/A & $11 / 01 / 96$ \\
\hline
\end{tabular}

\footnotetext{
Fonte: Elaborada pelos autores.
} 
Tabela 2. Amostra final de ações ordinárias analisada.

\begin{tabular}{rlcclc}
\hline \multicolumn{1}{c}{ Companhia } & Código & $\mathrm{N}^{\circ}$ & Companhia & Código \\
\hline 1 & Sadia S/A & SDIA3 & 15 & Telemar S/A & TNLP3 \\
2 & Aços Villares S/A & AVIL3 & 16 & Embraer S/A & EMBR3 \\
3 & Cemig S/A & CMIG3 & 17 & Embratel Part. S/A & EBTP3 \\
4 & Gerdau S/A & GGBR3 & 18 & Brasil Telecom S/A & BRT03 \\
5 & CVRD S/A & VALE3 & 19 & CVRD S/A & VALE3 \\
6 & Brasil Telecom S/A & BRT03 & 20 & Acesita & ACES3 \\
7 & Belgo-Mineira (Arcelor) & ARCE3 & 21 & Cemig S/A & CMIG3 \\
8 & Caemi S/A & CMET3 & 22 & Telesp S/A & TELP3 \\
9 & Lojas Americanas & LAME3 & 23 & Brahma S/A & AMBV3 \\
10 & Ambev S/A & AMBV3 & 24 & Belgo-Mineira (Arcelor) & ARCE3 \\
11 & Copel Participações S/A & CPLE3 & 25 & Eternit S/A & ETER3 \\
12 & CSN S/A & CSNA3 & 26 & Acesita S/A & ACES3 \\
13 & Aracruz Celulose S/A & ARQZ3 & 27 & Avipal S/A & AVPL3 \\
14 & Petrobras S/A & PETR3 & & & \\
\hline
\end{tabular}

Fonte: Elaborada pelos autores.

Tabela 3. Amostra final de ações preferenciais analisada.

\begin{tabular}{|c|c|c|c|c|c|}
\hline $\mathrm{N}^{\circ}$ & Companhia & Código & $\mathrm{N}^{0}$ & Companhia & Código \\
\hline 1 & Sadia S/A & SDIA4 & 32 & Acesita S/A & ACES4 \\
\hline 2 & Cemig S/A & CM1G4 & 33 & Perdigão S/A & PRGA4 \\
\hline 3 & WEG S/A & WEGE4 & 34 & Cemig S/A & CMIG4 \\
\hline 4 & Suzano Papel e Celulose S/A & SUZB5 & 35 & Sadia S/A & SDIA4 \\
\hline 5 & VCP & VCPA4 & 36 & Telesp S/A & TELP4 \\
\hline 6 & Ripasa & RIPA4 & 37 & Globex Utilidades S/A & GLOB4 \\
\hline 7 & Gerdau S/A & GGBR4 & 38 & Alpargatas/Santista S/A & AlPA4 \\
\hline 8 & CVRD S/A & VALE5 & 39 & Marcopolo S/A & POM04 \\
\hline 9 & Brasil Telecom S/A & BRT04 & 40 & Gerdau S/A & GGBR4 \\
\hline 10 & Belgo-Mineira (Arcelor) & ARCE4 & 41 & VCP S/A & VCPA4 \\
\hline 11 & Petrobras Química S/A & PTQS4 & 42 & Brahma S/A & AMBV4 \\
\hline 12 & Caemi S/A & CMET4 & 43 & Usiminas S/A & USIM4 \\
\hline 13 & Coteminas S/A & CTMN4 & 44 & Cia. Brasileira Distribuição (CBD) & PCAR4 \\
\hline 14 & Lojas Americanas & LAME4 & 45 & Gerdau Metalúrgica S/A & GOAU4 \\
\hline 15 & Ambev S/A & AMBV4 & 46 & Cataguazes Leopoldina S/A & FLFC5 \\
\hline 16 & Ultrapar Participações S/A & UGPA4 & 47 & Brasmotor S/A & ВMT04 \\
\hline 17 & Aracruz Celulose S/A & ARQZ4 & 48 & Whirlpool / Multibrás S/A & WHRL4 \\
\hline 18 & Saraiva S/A & SLED4 & 49 & Bombril S/A & BOBR4 \\
\hline 19 & Petrobras S/A & PETR4 & 50 & Coteminas S/A & CTMN4 \\
\hline 20 & Telemar S/A & TNLP4 & 51 & Trikem S/A & CPCA4 \\
\hline 21 & Gerdau Metalúrgica S/A & GOAU4 & 52 & Paranapanema S/A & PMAM4 \\
\hline 22 & Fras-le S/A & RAPT4 & 53 & Inepar Construções S/A & 1NEP4 \\
\hline 23 & Braskem S/A & BRKM5 & 54 & Estrela S/A & ESTR4 \\
\hline 24 & Metal Leve S/A & LEVE4 & 55 & Acesita S/A & ACES4 \\
\hline 25 & Embraer S/A & EMBR4 & 56 & CST S/A & CSBT4 \\
\hline 26 & Suzano Papel e Celulose S/A & SUZB5 & 57 & Avipal S/A & AVPL4 \\
\hline 27 & Embratel Part. S/A & EBTP4 & 58 & Belgo-Mineira (Arcelor) & ARCE4 \\
\hline 28 & WEG S/A & WEGE4 & 59 & Randon Participações S/A & RAPT4 \\
\hline 29 & Klabin S/A & KLBN4 & 60 & Fras-le S/A & RAPT4 \\
\hline 30 & Brasil Telecom S/A & BRT04 & 61 & Acesita S/A (adquirida) & ACES4 \\
\hline 31 & CVRD S/A & VALE5 & & & \\
\hline
\end{tabular}

Fonte: Elaborada pelos autores.

\section{Resultados}

\subsection{Análise descritiva da amostra}

A Tabela 4 apresenta a distribuição setorial das empresas da amostra, observando-se a quantidade de processos de F\&As analisados, baseada na classificação da BM\&FBovespa. As empresas dos setenta e dois processos analisados distribuem-se entre dezenove setores da economia com destaque para siderurgia/metalurgia $(21,05 \%)$ e alimentos/ bebidas e papel e celulose $(9,21 \%)$. 0 valor total aproximado em US\$ das operações das quais foi possível identificar o valor da transação, 
Tabela 4. Distribuição setorial das empresas da amostra.

\begin{tabular}{|c|c|c|c|c|}
\hline $\mathrm{N}^{\circ}$ & Setor & Quantidade Processos & Participação (\%) & Valor dos Processos (US\$) \\
\hline 1 & Alimentos e Bebidas & 7 & $9,21 \%$ & 1.744.398.756,00 \\
\hline 2 & Bens Industriais & 6 & $7,89 \%$ & 160.637.218,00 \\
\hline 3 & Brinquedos e Jogos & 1 & $1,32 \%$ & N. D. \\
\hline 4 & Comércio (Varejo) & 5 & $6,58 \%$ & $316.459 .854,00$ \\
\hline 5 & Construção e Montagem & 2 & $2,63 \%$ & $211.670 .669,00$ \\
\hline 6 & Editorial & 1 & $1,32 \%$ & $2.604 .791,00$ \\
\hline 7 & Eletroeletrônicos & 4 & $5,26 \%$ & $484.000 .000,00$ \\
\hline 8 & Energia Elétrica & 4 & $5,26 \%$ & $629.823 .003,00$ \\
\hline 9 & Indústria Aeronáutica & 1 & $1,32 \%$ & N. D. \\
\hline 10 & Mineração & 3 & $3,95 \%$ & $3.822 .960 .417,00$ \\
\hline 11 & Papel e Celulose & 7 & $9,21 \%$ & $1.984 .100 .000,00$ \\
\hline 12 & Petróleo e Gás & 2 & $2,63 \%$ & 746.051.402,00 \\
\hline 13 & Produtos Limpeza & 1 & $1,32 \%$ & $380.000 .000,00$ \\
\hline 14 & Química e Petroquímica & 4 & $5,26 \%$ & 1.155.726.247,00 \\
\hline 15 & Siderurgia / Metalurgia & 16 & $21,05 \%$ & 2.937.736.780,00 \\
\hline 16 & Telecomunicações & 5 & $6,58 \%$ & $1.018 .934 .183,00$ \\
\hline 17 & Têxtil / Calçados & 4 & $5,26 \%$ & $23.811 .751,00$ \\
\hline 18 & Veículos e Peças & 2 & $2,63 \%$ & $132.327 .476,00$ \\
\hline 19 & Vestuário & 1 & $1,32 \%$ & N. D. \\
\hline \multicolumn{2}{|c|}{ Total de Processos Analisados } & 72 & $100 \%$ & $15.751 .242 .547,00$ \\
\hline
\end{tabular}

considerando as empresas participantes da amostra, foi de US\$15,751 bilhões.

Quanto à classificação das F\&As analisadas, no que se refere ao setor de atuação, houve uma prevalência de F\&As do tipo horizontal, 67 (93,06\%) dos 72 processos, contra apenas $4(5,56 \%)$ do tipo vertical e um $M B O(1,38 \%)$ da Estrela S/A. Em relação à origem dos países das empresas envolvidas, a maioria dos processos se refere a apenas empresas brasileiras $55(72,37 \%)$ e 21 (27,63\%) compreendendo empresas brasileiras e estrangeiras (F\&A cross-border), das quais, em 16 (21,05\%), foram empresas brasileiras adquirindo empresas de economias importantes, como Estados Unidos e China, e de países da América Latina (Panamá, México, Chile, Peru e principalmente a Argentina). A origem das empresas estrangeiras que compraram as cinco $(6,58 \%)$ empresas brasileiras participantes da amostra foram: Bélgica, França e Estados Unidos.

\subsection{Análise da eficiência do mercado e do insider trading}

Conforme descrito na seção anterior, o teste da HEM para os anúncios de F\&As brasileiras foi realizado tanto para ações preferenciais ( $\mathrm{N}=61)$ quanto para as ações ordinárias $(\mathrm{N}=27)$. Essa disparidade de ações da amostra é explicada pela maior liquidez ainda existente das primeiras em relação às segundas no mercado brasileiro. As Tabelas 5 e 6 apresentam os resumos das estatísticas dos retornos anormais na janela estudada, que compreendeu os dias $t_{-5}$ até $t_{+5}$. Neste caso, a hipótese da eficiência de mercado seria confirmada se não fossem encontrados retornos anormais significantes e diferentes de zero, nos dias $t_{0}$ e $t_{+1}$, sinalizando que o mercado comportou-se de maneira eficiente, no que se refere à rapidez e precisão da incorporação do anúncio de uma F\&A nos preços das ações analisadas. Além disso, retornos anormais acumulados com significância estatística nos dias anteriores à F\&A poderiam ser entendidos como vazamento de informações ao mercado, ou seja, indícios claros da prática de insider trading.

Analisando os retornos anormais acumulados das ações preferenciais da Tabela 5 destaca-se, inicialmente, o aumento desvio padrão das ações no dia da divulgação da F\&A e, principalmente, nos dois dias seguintes $\left(t_{0}, t_{+1} e t_{+2}\right)$, sinalizando que a divulgação de uma $F \& A$ ao mercado é um evento corporativo relevante, que contém conteúdo informacional que influencia a precificação das ações no mercado. Em outras palavras, o aumento da volatilidade da cotação (retorno) no dia e nos dois dias seguintes mostra o impacto que a divulgação da F\&A causou nas expectativas dos investidores, e a tentativa (reação) do mercado em fazer a leitura correta (determinação do preço justo) para a cotação da ação, diante do novo quadro informacional.

Considerando um nível de significância de 5\% ( $p$-value $<0,05)$, foram encontrados retornos anormais estatisticamente diferentes de zero, somente no dia $t_{+3}$. Tal constatação leva à rejeição de $\mathrm{H}_{0}$ de 
Tabela 5. Resumo das estatísticas t dos retornos anormais $\left(\overline{R A A}_{-5,+5}\right)$ das ações preferenciais.

\begin{tabular}{ccccccc}
\hline Dia & No Empresas & Média (LN) & Média (\%) & Desvio Padrão & Erro Padrão & $p$-value* \\
\hline-5 & 61 & $-0,0046501$ & 0,995 & 0,03663390 & 0,00469049 & 0,325 \\
-4 & 61 & $-0,0012162$ & 0,999 & 0,03082052 & 0,00394616 \\
-3 & 61 & 0,0013664 & 1,001 & 0,03598863 & 0,00460787 & 0,759 \\
-2 & 61 & 0,0007382 & 1,001 & 0,02965411 & 0,00379682 & 0,768 \\
-1 & 61 & $-0,0026064$ & 0,997 & 0,02956628 & 0,00378557 \\
0 & 61 & $-0,0039959$ & 0,996 & 0,04076728 & 0,00521971 \\
+1 & 61 & $-0,0053239$ & 0,995 & 0,05304988 & 0,00679234 \\
+3 & 61 & 0,0102917 & 1,010 & 0,06189876 & 0,00792532 \\
+4 & 61 & $-0,0117666$ & 0,988 & 0,03541459 & 0,00453437 & 0,436 \\
+5 & 61 & 0,0014066 & 1,001 & 0,02549859 & 0,00326476 \\
\hline
\end{tabular}

${ }^{*}{ }^{*} p$-value $<0,05$ rejeita-se a hipótese de média igual a zero. Fonte: Elaborada pelos autores.

Tabela 6. Resumo das estatísticas t dos retornos anormais $\left(\overline{R A A}_{-5,+5}\right)$ das ações ordinárias.

\begin{tabular}{|c|c|c|c|c|c|c|}
\hline Dia & $N^{\circ}$ Empresas & Média (LN) & Média (\%) & Desvio Padrão & Erro Padrão & $p$-value \\
\hline-5 & 27 & $-0,00244286$ & 0,998 & 0,03650162 & 0,00702474 & 0,731 \\
\hline-4 & 27 & $-0,00706071$ & 0,993 & 0,02753629 & 0,00529936 & 0,194 \\
\hline-3 & 27 & 0,01015144 & 1,010 & 0,02993363 & 0,00576073 & 0,090 \\
\hline-2 & 27 & 0,00196722 & 1,002 & 0,03595038 & 0,00691865 & 0,778 \\
\hline-1 & 27 & $-0,00820466$ & 0,992 & 0,03493903 & 0,00672402 & 0,233 \\
\hline 0 & 27 & 0,00430415 & 1,004 & 0,02410801 & 0,00463959 & 0,362 \\
\hline+1 & 27 & 0,00523925 & 1,005 & 0,03949747 & 0,00760129 & 0,497 \\
\hline+2 & 27 & $-0,00070835$ & 0,999 & 0,04273269 & 0,00822391 & 0,932 \\
\hline+3 & 27 & $-0,01392763$ & 0,986 & 0,03094310 & 0,00595500 & $0,027^{*}$ \\
\hline+4 & 27 & 0,00097491 & 1,001 & 0,02447766 & 0,00471073 & 0,838 \\
\hline+5 & 27 & $-0,00143157$ & 0,999 & 0,03316895 & 0,00638337 & 0,824 \\
\hline
\end{tabular}

(*) $p$-value $<0,05$ rejeita-se a hipótese de média igual a zero. Fonte: Elaborada pelos autores.

que o RAA é diferente de zero, principalmente em $t_{0}$ e $t_{+1}$, sinalizando que o mercado comportou-se de maneira eficiente, fazendo os devidos ajustes de preços quando da divulgação da $\mathrm{F} \& A$, não permitindo que investidores auferissem ganhos acima do mercado em negociações com essa informação. Isso equivale a dizer, conforme Haugen (1995), que o conteúdo informacional do anúncio de F\&As no período estudado não alterou o retorno esperado de investimentos no mercado.

No que se refere ao RAA das ações ordinárias apresentado na Tabela 6 , considerando também um nível de significância de 5\% ( $p$-value<0,05), foram encontrados retornos anormais estatisticamente diferentes de zero, no dia $t_{+3}$. Constatação que também leva à rejeição de $\mathrm{H}_{0}$ de que a média é diferente de zero, principalmente em $t_{0}$ e $t_{+1}$, sinalizando que o mercado é informacionalmente eficiente.

De maneira semelhante às ações preferenciais, ocorreu um aumento desvio padrão das ações nos dois dias seguintes à divulgação da $F \& A$ $\left(t_{+1}\right.$ e $\left.t_{+2}\right)$, sinalizando que a divulgação de uma F\&A ao mercado é um evento corporativo relevante, que contém conteúdo informacional que influencia as expectativas dos investidores e, consequentemente, a precificação das ações no mercado.

A não significância do RAA nos dias $t_{+1}$ e $t_{+2}$ e a sua significância estatística no dia $t_{+3}$, além do aumento da volatilidade dos retornos no dia e nos dois seguintes ao anúncio da F\&A podem ser interpretados como uma reação/ajuste rápido do mercado ao anúncio da F\&A (eficiência), mas não de maneira precisa, com a correção sendo feita no dia $t_{+3}$. Dessa forma, pode-se dizer que o mercado comportou-se de maneira eficiente no que se refere à velocidade do ajuste à nova informação, mas de maneira não tão eficiente quando se trata da direção e magnitude do ajustamento dos preços (Copeland \& Weston, 1988).

A análise do RAA no dia e no dia seguinte ao anúncio da F\&A, conforme assinala Firth (1980), fornece uma medida direta do impacto econômico desse evento, bem como uma medida direta do aumento ou redução na riqueza dos acionistas. Pode-se observar uma disparidade no comportamento das ações preferenciais e ordinárias. Enquanto que nas PN ocorreu uma queda, para as $\mathrm{ON}$ ocorreu um 
aumento do RAA ou da riqueza, conforme pode ser observado na Figura 2. Uma possível explicação para isso seria o prêmio pago para essas últimas, pois, em muitas das F\&As analisadas, ocorreu apenas a transferência de controle (takeover), no qual geralmente há um prêmio pago aos controladores, que, dependendo do ano da F\&A (após 2001) e do estatuto da empresa, pode ser extensivo em parte $(80 \%)$ aos acionistas minoritários das ações ON (tag along).

Comparando os resultados com as pesquisas da literatura nacional, esses contrariam os de Bueno et al. (2000) e de Camargos \& Barbosa (2006), estudos nos quais o mercado não se comportou de maneira eficiente no período analisado. Entretanto, vão na direção dos resultados encontrados por Camargos \& Barbosa (2007), que encontrou evidências favoráveis à HEM na forma semiforte. Essas divergências e similaridades de resultados se explicam, por um lado, pela forma de cálculo do retorno anormal, na amostra e no período analisado, por outro, é salutar, pois enriquecem o debate sobre o tema e o corpo de evidências empíricas, fornecendo assim, no seu conjunto, um panorama da HEM no contexto de anúncios de $\mathrm{F} \& A s$ no mercado brasileiro.

No que se refere à análise da prática de insider trading, destaca-se que, se for considerado um nível de significância de $10 \%$, o dia $t_{-3}$ foi o que apresentou o maior RAA, fornecendo, aparentemente, fortes indícios de que a notícia da F\&A tenha sido antecipada ao mercado, a partir da qual alguns agentes com acesso privilegiado (que tenham participado das assembleias de acionistas que as deliberaram) possivelmente tenham se utilizado dessa posição para auferir ganhos anormais no mercado, em detrimento de outros.

A prática do insider trading é condenável por vários motivos, dentre eles: 1 . Criam oportunidades de alguns investidores lucrarem em detrimento de outros; 2. Levam a uma transferência de riqueza,

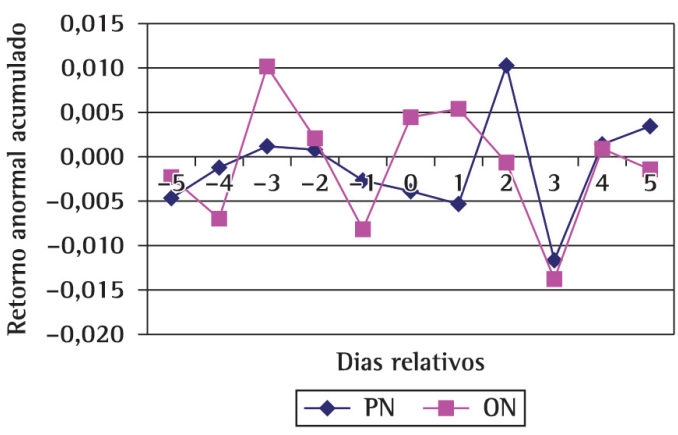

Figura 2. Comportamento do RAA para ações PN e ON na janela estudada. Fonte: Elaborada pelos autores. principalmente entre os acionistas minoritários (outsiders) e majoritários (insiders) (Demsetz, 1986); 3. Criam uma imagem negativa do mercado, em um momento em que as entidades operadoras e reguladoras (BM\&FBovespa e Comissão de Valores Mobiliários) vêm empreendendo esforços para melhorar a transparência nas negociações por meio da adoção de práticas de governança corporativa, visando sua consolidação como um dos principais centros mundiais de negociação de títulos.

\section{Considerações finais e conclusão}

Neste artigo, foi analisada a reação do mercado de capitais brasileiro quando do anúncio de processos de F\&As, no intuito de aferir sua eficiência em termos informacionais (forma semiforte). Para isso, foram calculados e analisados retornos anormais de uma amostra de 61 ações preferenciais e 27 ordinárias, quando do anúncio de F\&As de empresas brasileiras ocorridas entre janeiro de 1996 e dezembro de 2004. A significância estatística do retorno anormal foi realizado mediante a aplicação do teste t.

Foi constatado que o anúncio de uma F\&A contém um conteúdo informacional relevante para a precificação das ações no mercado, identificado pelo aumento do desvio padrão na data da sua divulgação $(\mathrm{PN})$ e nos dois dias seguintes (ON e PN). Isso pode ser explicado pela complexidade e impactos que tal evento gera nas empresas envolvidas, na comunidade e na economia, pois um processo de F\&A afeta a distribuição da riqueza gerada pelas organizações e a estrutura de propriedade, resultando em novos arranjos organizacionais (economia e governança corporativa), envolve os incentivos para que os participantes diretos desse processo se empenhem em atingi-la (agência) e diz respeito também à forma de se conduzir o negócio (estratégia organizacional). Em suma, afetam as rotinas e processos internos, bem como causam rearranjos nas expectativas dos investidores e, muitas vezes, das condições do mercado. 0 aumento da volatilidade do RAA mostra o impacto que a divulgação da F\&A causou nas expectativas dos investidores, e a tentativa (reação) do mercado em fazer a leitura correta (determinação do preço justo) para a cotação da ação, diante da nova realidade informacional.

Foram encontrados retornos anormais estatisticamente diferentes de zero somente no dia $t_{+3}\left(\mathrm{PN}\right.$ e $\mathrm{ON}$ ), levando à rejeição de $\mathrm{H}_{0}$, que seria confirmada se fossem encontrados retornos anormais acumulados diferentes de zero, principalmente em $t_{0}$ e $t_{+1}$, sinalizando que o mercado comportou-se de maneira eficiente informacionalmente, tanto para as ações preferenciais quanto para as ordinárias. 
Ponderando-se, entretanto, que essa eficiência foi observada na velocidade do ajuste à nova informação, mas questionável quando se trata da direção e magnitude do ajustamento dos preços, quando se considera o RAA com significância estatística para ambas as ações no dia $t_{+3}$ (Copeland \& Weston, 1988).

Foi constatada uma disparidade no comportamento do RAA das ações $\mathrm{PN}$ e $\mathrm{ON}$ no dia e no dia seguinte ao anúncio da $\mathrm{F} \& \mathrm{~A}$, com uma queda para as primeiras e uma elevação para essas últimas, reflexo do tipo de F\&As (takeover) e da legislação brasileira após a reforma da Lei 6.404/76 em 2001, que ampliou a abrangência do mecanismo tag along.

Os retornos anormais acumulados por dia e por séries de observações na janela de evento forneceram indícios de possíveis vazamentos de informações no dia $t_{-3}$, prática prejudicial ao mercado, no sentido de depor contra a transparência e a igualdade de acesso a informações que um mercado deve apresentar na perspectiva de boas práticas de governança corporativa.

Enfim, diante da discussão e confronto de resultados sobre o tema e cientes de que a validade da HEM é estabelecida pela acumulação de evidências empíricas do ajustamento dos preços a diversos tipos de evento (Fama, 1970), esta pesquisa vem se juntar a um mosaico de resultados, obtidos com diferentes eventos corporativos relevantes, que sozinhos não explicam o todo, mas em conjunto enriquecem o debate e possibilitam uma visão panorâmica da evolução do mercado de capitais brasileiro.

\section{Referências}

Berle Junior, A. A., \& Means, G. C. (1932). The modern corporation and private propriety. New York: Macmillan.

Brasil. (1976, December 17). Dispõe sobre as Sociedades por Ações (Lei $n^{\circ}$. 6.404, de 15 de dezembro de 1976). Diário Oficial da União.

Brasil. (2001, November 1). Altera e acrescenta dispositivos na Lei no 6.404 e na Lei no 6.385 (Lei $n^{\circ} .10 .303$, de 31 de outubro de 2001). Diário Oficial da União.

Brealey, R. A., \& Myers, S. C. (1995). Princípios de finanças empresariais. Portugal: McGraw Hill. 924 p.

Brown, S. J., \& Warner, J. B. (1980). Measuring security price performance. Journal of Financial Economics, 8(3), 205258. http://dx.doi.org/10.1016/0304-405X(80)90002-1.

Brown, S. J., \& Warner, J. B. (1985). Using daily stock returns. Journal of Financial Economics, 14(1), 3-31. http:// dx.doi.org/10.1016/0304-405X(85)90042-X.

Bueno, A. F., Braga, R. F. R., \& Almeida, R. J. (2000). Pesquisa sobre a eficiência informacional no mercado brasileiro nos casos de fusões e aquisições. In Anais do 24 Encontro Nacional de Programas de Pós-Graduação em Administração, Florianópolis, SC. Rio de Janeiro: ANPAD.
Camargos, M. A., \& Barbosa, F. V. (2003). Estudos de evento: teoria e operacionalização. Caderno de Pesquisas em Administração USP, 10(3), 1-20.

Camargos, M. A., \& Barbosa, F. V. (2006). Eficiência informacional do mercado de capitais brasileiro pósplano real: um estudo de eventos dos anúncios de fusões e aquisições. Revista de Administração USP, 41(1), 67-83.

Camargos, M. A., \& Barbosa, F. V. (2007). Análise empírica do retorno acionário anormal e da reação do mercado de capitais brasileiro aos anúncios de fusões e aquisições ocorridos entre 1994 e 2001. Revista de Administração USP, 42(4), 468-481.

Campbell, J. Y., Lo, A. W., \& Mackinlay, A. C. (1997). The econometrics of financial markets (2nd ed.). New Jersey: Princeton University Press. 611 p.

Cooper, D. R., \& Schindler, P. S. (2003). Métodos de pesquisa em administração (7. ed.). Porto Alegre: Bookman. 640 p.

Copeland, T. E., \& Weston, J. F. (1988). Financial theory and corporate policy (3rd ed.). Addison-Wesley Publishing Company. $447 \mathrm{p}$.

Cordeiro, F. F., Perobelli, F. S., \& Arbex, M. A. (1999). Expectativas racionais e eficiência informacional: análise do mercado acionário brasileiro num cenário de regras no período 1997-1999. In Anais do 23 Encontro Nacional de Programas de Pós-graduação em Administração, Foz do lguaçu, PR. Rio de Janeiro: ANPAD.

Demsetz, H. (1986). The market for corporate control: corporate control, insider trading, and rates return. The American Economic Review, 76(2), 313-316.

Eizirik, N. (1983). Insider trading e responsabilidade de administrador de companhia aberta. Revista de Direito Mercantil, Industrial, Econômico e Financeiro, 22(50),4256.

Fama, E. F. (1970). Efficient capital markets: a review of theory and empirical work. The Journal of Finance, 25(2), 383-417. http://dx.doi.org/10.2307/2325486.

Firth, M. (1980). Takeovers shareholders returns, and the theory of the firm. The Quarterly Journal of Economics, 94(2), 235-260. http://dx.doi.org/10.2307/1884539.

Halpern, P. J. (1983). Corporate acquisitions: a theory of special cases? A review of studies applied to acquisitions. The Journal of Finance, 38(2), 297-317. http://dx.doi. org/10.2307/2327962.

Haugen, R. (1995). The new finance: the case against efficient markets. 5. ed. New Jersey: Prentice Hall. 146 p.

Jensen, M. (1978). Some anomalous evidence regarding market efficiency. Journal of Financial Economics, 6(1), 95-101. http://dx.doi.org/10.1016/0304405X(78)90025-9.

Jovanovic, B., \& Rousseau, P. (2002). The q-theory of mergers. The American Economic Review, 92(3), 198204. http://dx.doi.org/10.1257/000282802320189249.

Kloeckner, G. 0. (1995). Estudos de evento: a análise de um método. In Anais do 19 Encontro Nacional de Programas de Pós-graduação em Administração (pp. 261-270), João Pessoa, PB. Rio de Janeiro: ANPAD

KPMG. (2010). Pesquisa de fusões e aquisições: espelho das transações realizadas no Brasil. $4^{\circ}$ trimestre e acumulado, 2011. São Paulo: KPMG. Retrieved from http://www. kpmg.com.br/publicacoes/fusoes_aquisicoes/2010.pdf.

Leite, H., \& Sanvicente, A. Z. (1990). Valor patrimonial: usos, abusos e conteúdo informacional. Revista de 
Administração de Empresas, São Paulo, 30(3), 17-31. http://dx.doi.org/10.1590/S0034-75901990000300003.

Martins, G. A. (2002). Manual para elaboração de monografias e dissertações (3. ed.). São Paulo: Atlas. 134 p.

Novis Neto, J. A., \& Saito, R. (2002). Dividend yields e persistência de retornos anormais das ações: evidência do mercado brasileiro. In Anais do 26 Encontro Nacional de Programas de Pós-graduação em Administração, Salvador, BA. Rio de Janeiro: ANPAD.

Perobelli, F. F. C., \& Ness Junior, W. L. (2000). Reações do mercado acionário a variações inesperadas nos lucros das empresas: um estudo sobre a eficiência informacional no mercado brasileiro. In Anais do 24 Encontro Nacional de Programas de Pós-graduação em Administração, Florianópolis, SC. Rio de Janeiro: ANPAD.

Pinto Junior, H. Q., \& lootty, M. (2005). Avaliando os impactos microeconômicos das fusões e aquisições nas indústrias de energia no mundo: uma análise para a década de 90 . Revista de Economia Política, 25(4), 439-53.

Procianoy, J. L., \& Antunes, M. A. (2001). Os efeitos das decisões de investimento das firmas sobre os preços de suas ações no mercado de capitais. In Anais do 25 Encontro Nacional de Programas de Pós-graduação em Administração, Campinas, SP. Rio de Janeiro: ANPAD.

Roberts, H. (1967). Statistical versus clinical prediction of the stock market. In Conference of Securities Price Analysis, Chicago.

Ross, S. A., Westerfield, R. W., \& Jaffe, J. F. (2002). Administração financeira: corporate finance (2. ed.). São Paulo: Atlas. 776 p.

Scherer, F. M., \& Ross, D. (1990). Industrial market structure and economic performance (3rd ed.). Boston: Houghton Mifflin Company. 713 p.

Schiehll, E. (1996). 0 efeito da divulgação das demonstrações contábeis no mercado de capitais brasileiro: um estudo sobre a variação no preço das ações. In Anais do 27 Encontro Nacional de Programas de Pós-graduação em Administração (pp. 289-303), Angra dos Reis, RJ. Rio de Janeiro: ANPAD.

Waack, R. S. (2000). Fusões e aquisições na indústria farmacêutica-veterinária. Caderno de Pesquisas em Administração, 7(3), 82-98.

\section{Market efficiency hypothesis of the brazilian stock market in merger and acquisitions announcements}

\section{Abstract}

This paper aims is to analyze the behavior of stock prices of publicly traded Brazilian companies listed on the BM\&FBovespa the day after the announcements of mergers and acquisitions (M\&As) to measure the semi-strong form of the Market Efficiency Hypothesis of the Brazilian market. This study considered an event in which the daily abnormal returns were calculated using the model of market-adjusted return. The sample consisted of 61 preferred and 27 common shares of Brazilian companies participating in processes of M\&A between January 1996 and December 2004. The results indicated that 1 . The announcement of an M\&A event contains information relevant to the pricing of shares in the market; 2 . The possible use of inside information; 3 . The Brazilian market is represented by the semi-strong form of the Market Efficiency Hypothesis, both for preferred shares and for the ordinary shares, with regard to the speed of adjustment to announcement; 4 . The market reacted differently to common and preferred shares, decreasing for the former and increasing for the latter.

\section{Keywords}

Market efficiency. Mergers and acquisitions. Event study. Insider trading. 